\title{
A SURVEY OF UNIVERSITY STUDENT ATTITUDES TOWARD THE LANGUAGE LAB
}

\begin{abstract}
This article reports the results of a survey of student attitudes toward the language lab at Southern Illinois University at Carbondale. The report notes that an initial positive attitude toward the lab in the first semester becomes more negative during the second. The author suggests a need for new lab materials that maintain the initial favorable attitude towards the lab.
\end{abstract}

KEY WORDS: foreign language, language lab, language lab materials, student attitudes.

This paper describes a survey conducted to ascertain student attitudes toward the language lab at Southern Illinois University at Carbondale.

Language labs have again become a focus of interest in the profession at large over the last few years, a development most of us would not have predicted from our experience. The literature contains a growing consensus that language labs have been misused and underused in the past, and that this is the root of their relative unpopularity and questionable efficacy. Nonetheless, the lab has a definite contribution to make to foreign/second language acquisition and learning in the eighties. The new vision sees the lab, enriched by video and computer technology, and no longer married to the audiolingual method, as a resource center that may be used to supplement classroom work: extra drill, grammar practice, remedial programs, cultural enrichment, and exposure to the real language through authentic audio and video documents. It is not the technology, but the pedagogical use of the technology, that determines the effectiveness of the lab, however (Taggart, 1980; Sheehan, 1980; Paramskas, 1980; Davies, 1982; Freire and Kunzel, 1983).

The prevalent opinion, then, is that the language lab can be a useful and flexible tool in foreign and second language programs, but that before the lab can achieve its potential the way it is used must be thought through carefully and new types of materials must be

David A. Bedford is Language Lab Director for the Department of Foreign Languages and Literatures at Southern Illinois University at Carbondale.

The assistance of Vincent A. Lacey, Director of the Computer Assisted Instruction and Research Laboratory, in using the computer to perform the statistical tests is gratefully acknowledged. 
developed for it. As this renewal process is being carried out, it is of utmost importance to understand how students perceive language labs and how they feel about them.

Unfortunately, very little work has been done to survey university students for their attitudes toward labs. Schotta (1973) describes a questionnaire on attitudes given to students at a state university. The instrument contained nine items which were to be answered on a bipolar scale of yes or no. The responses were grouped by languages and then compared. No inferential statistics are presented. The principal purpose of the article is to explore the relationship between student attitudes concerning the lab and the overall program of the foreign language department of this unnamed state-supported university.

A suggestive study is presented by Pill (1974). On an instrument for student evaluation of teachers, three questions were included to obtain the students' assessment of the language lab. All questions were answered on a five-point Likert scale. The assessment of the lab given by first, second, and third year students was compared to the assessment they gave of their teachers. The first year students, who used commercially produced lab materials, rated the lab far below their teachers. Second and third year students, who used primarily or exclusively lab materials developed by Pill for those courses, rated the lab almost as highly as their teachers. These ratings are taken to mean that students favor homemade tapes (Pill's term), though Pill cautions that first year students are fulfilling a language requirement, while the rest are not; therefore, care is required in interpretation. Again, no inferential statistics are included.

More recently, Lawrason and Lugo (1979) presented a survey of college students' attitudes concerning the language lab. The instrument contained twenty questions answered on a five-point Likert scale, nine questions eliciting student information, and one open-ended question requesting comments. An overall attitude score was computed, and the answers to each item were analyzed. For each, a chi-square test was used to compare the frequency of responses of lab users to those of lab non-users (i.e., how many lab users marked answer $a$, how many $b$, how many $c$, etc., versus how many lab non-users marked $a$, etc.). Significant tests were obtained on three of the twenty items. The authors concluded that most students favor the language lab, but that the large number of $c$ responses ("undecided") makes analysis difficult to interpret. (See the same article for a review of similar surveys of high school students.)

The present report concerns a survey of foreign language students conducted during the Spring semester of 1984. 
The population surveyed included all students of foreign languages in courses that use the language lab at Southern Illinois University at Carbondale, a large state-supported institution. First year courses dominate the foreign language enrollment, as only one year of foreign language study is required, and that not by all colleges.

\section{The Instrument}

The questionnaire, which was administered by the instructors in the classes and filled out anonymously, requested answers to three questions only. The first asked for the student's course. The second asked "Do you like coming to the language lab?" Students answered either yes or no by checking the appropriate box. Finally, space was given for comments.

\section{The Language Lab}

The language lab at Southern Illinois University is really two labs in one room. One half is used by students of the Center for English as a Second Language. They meet in classes with an instructor who monitors them. The booths in this half function as an audio-active lab. The same booths may be used for dial access when classes are not in session.

The other half of the language lab is used by foreign language students. Booths in this portion may be used for dial access (in which case the booth functions in audio-active mode) or to play an individual tape (in which case the booth functions in either audioactive or audio-active-comparative mode). Dial access is used very little by foreign language students.

\section{Results}

The total number of respondents, after discards, was 425. Discarded were questionnaires in which neither a yes or no answer was marked, and those in which both answers were marked.

Comparisons were made between languages, between years (first year students, second year students, etc.) and between semesters. Comments were tabulated and analyzed statistically where possible. In all cases, comparisons refer to how many students in each language (or year, or semester) answered yes and how many answered no; therefore, the statistical test chosen was chi-square.

Of 425 respondents, $189(44.5 \%)$ answered yes and $236(55.5 \%)$ answered no. Comparisons between years showed no statistically significant differences. As a matter of fact, the difference between first and second year, tested by means of chi-square, yielded a probability of $1.0(X 2=0.0$, d.f. $=1 . N=418)$, indicating near perfect agreement between first year and second year students on their attitude toward the lab. 
Two sets of comparisons did yield significant differences, however. The first set compared languages (Table 1). Chi-square was $21.33(8, N=425, p-.01)$. In addition, the languages were grouped into commonly taught (French, German, Russian, Spanish) and less commonly taught (Chinese and Japanese), and compared (Table 2). The probability was higher, but still significant $(-.05)$, with students of the less commonly taught languages favoring the lab more than the other students. The self-instructional languages (Italian and Portuguese) were not included in the second analysis owing to the low $n$.

The second set of comparisons with significant results dealt with the semester of enrollment. Answers of all students in the first, second, and fourth semesters were compared. These semesters were selected because courses corresponding to other semesters had too few subjects for analysis. The chi-square was $37.89(2, N=411$, $p-.0001)$, indicating that attitudes vary considerably by semester. A visual examination of the data indicated that an attitude change takes place from the first semester (majority of yes answers) to the second (majority of no answers). Therefore the responses of students in first semester were compared to those of students in second semester (Table 3). Only Spanish and French students were used this time, as only those languages have first-semester courses during the Spring session. The chi-square test confirmed the supposition, because the difference between the first and second semesters was significant at the .0001 level $(X 2=39.01$, d.f. $=1, N=290)$.

As for the comments, they were tabulated and grouped into categories. Comments made by students who answered yes (i.e., who favored the lab) were separated from comments made by students who answered no (i.e., who disliked the lab). Where enough students made the same comment to allow statistical analysis, the frequency of yes students making the comment was compared to the frequency of no students making the same comment, again by means of the chi-square test. Three categories of comments showed statistically significant differences. These and other comments of interest are discussed below.

\section{Discussion}

The data show that students begin their first semester of foreign language study favorably disposed toward the language lab (yes: 85; no: 44). By the second semester the favorable disposition has vanished and students seem to develop an aversion to using the lab (yes: 84 ; no: 171 ).

The finding that students of Chinese and Japanese favor the language lab far more than other students may be explained by their perception of these languages. Chinese and Japanese are viewed by many as exotic and exceedingly difficult as compared to the more commonly taught languages. Thus it is likely that students with low 
motivation toward languages will select themselves out of Chinese and Japanese when fulfilling the language requirement, leaving primarily the more motivated students. Thus this finding has a plausible explanation quite apart from the lab and its offerings and consistent with the experience of many professionals in the field.

The tabulation and analysis of comments offered valuable information. Two types of comment categories deserve attention; (1) those that were made by a large number of students, but that showed no significant difference in frequency between yes students and no students, thus indicating an area of concern to all regardless of attitudes; and (2) those that did show a significant difference between students who favor and those who dislike the lab (see Table 4).

First we turn our attention to comments of the first type, those that concerned all students regardless of attitude. The most frequent comment was the lack of time to attend the lab because of conflicts between the students' schedules and the hours of operation of the lab (42 comments). Next came complaints of noise interference coming primarily from classes being conducted in the same room. Some noise interference came from the hallway and from students working in adjacent booths ( 28 comments). Finally, there were compaints concerning equipment: uncomfortable headphones (27) and equipment malfunction/fuzziness of sound (21). Chi-squares computed for these categories of comments in no case reached the .05 level of significance. However, when all of those comments were grouped together (Table 5), chi-square did reach significance $(p-.025)$. The comments were more frequent among students who dislike the lab (i.e., answered no) than among those who favor the lab. The grouping together of these comments is justified in that all the comments point to circumstances beyond the students' control that prevent them from obtaining the full benefit of the lab.

The comments of the second type show marked distinctions between yes and no students. Fifty students made some sort of comment regarding the helpfulness of the lab (31 said it helped; 19 said it did not help). Those who saw the lab as helpful were generally students who like the lab ( 23 yes students made this comment, while only eight no students felt the lab was helpful). All nineteen students who said that the lab did not help answered no to the question on the survey. The chi-square test of these data was significant at the .001 level (Table 6). Finally, several students complained that the lab was boring. Of these, sixteen were no students and only one liked the lab $(p-.005)$.

Student comments appear to indicate that the perceived helpfulness of the work assigned for lab is crucial to student attitudes. If the lab materials are relevant to their coursework and/or their personal goal of speaking the language, students will like using the lab. If the lab materials are not relevant or are boring, the 
students become negative toward the lab. (See Schotta, 1973, p. 501). Students who are favorably inclined tend to "put up with" hindrances caused by scheduling problems, noise interferences, and minor equipment trouble, but these problems may tend to drive away unfavorable students. Indeed, the aggregate effect of such problems may be the cause, or partial cause, of negative attitudes in many students.

It is important to bear in mind that explanations advanced in survey studies such as the present one are largely speculative, and may not be entirely applicable to radically different student populations.

\section{Conclusion}

The following hypotheses attempt to account for the findings of the present survey.

(1) Students become negative toward using the lab when they do not perceive the materials as helping them to attain the objectives of their language courses.

(2) Students become negative toward using the language lab when they do not perceive the materials as helping them attain their personal goal of speaking the language.

(3) Students lose interest if the lab materials are boring.

(4) (a) Factors that reduce the full usefulness of the lab (schedule conflicts, noise interference, equipment malfunction, etc.) may be overcome in part by good materials (i.e., helpful, relevant, and not boring).

(b) Such factors always harm motivation and cannot be overcome if they go beyond a certain threshold of tolerance.

Hypotheses (1)-(3) may be tested by controlled studies combined with surveys of student attitudes. Hypothesis (4) implies that the materials are the most important factor in determining the effectiveness of the lab as a tool to aid second/foreign language acquisition and learning. This is consistent with the prevailing opinion in the literature, cited previously. As for scheduling, interference, and equipment problems, good management dictates that every effort be made to eliminate them or keep them at the minimum level possible, in any case.

The findings of this survey, given the overall negative feelings of the students, are not heartening on the one hand. On the other, they contain two elements of hope. The first is that students begin their language study with a favorable opinion of the lab. This leaves open the possibility that the favorable orientation can be maintained and nurtured in some way.

The second reason for hope is that student comments are consistent with the opinion that the language lab can be a tool of significant help to students, provided the right kind of materials are available to use in it. Current research recommends several kinds of 
materials, all rather closely related to each other; listening comprehension practice (Morley, 1980; Davies, 1982), authentic documents (Taggart, 1980), and acquisition-rich intake (Krashen and Terrell, 1983). The results reported in the present survey encourage us to develop these new materials. They indicate that our efforts may well be rewarded. The task before us now is to develop imaginative, pedagogically sound language lab materials and then to test them: to test their effect on student attitudes, but above all, to test their effect on the language proficiencv of our students.

\section{References}

Davies, N. (1982). Foreign/second language education and technology in the future. NALLD Journal, 16, no. 3-4, 5-14.

Freire, J. \& Kunzel, P. (1983). Second language research: implications and applications for the language laboratory. Hispania, 66, 386-391.

Krashen, S. \& Terrell, T. (1983). The natural approach: Language acquisition in the classroom. Oxford, England: Pergamon Press.

Lawrason, R. \& Lugo, C. (1979). Student attitudes towards language lab facilities at Temple University. NALLD Journal, 14, no. 1, 12-27.

Morley, J. (1980). Active participation/purposeful listening in the language laboratory: aspects of theory and practice. SPEAQ Journal, 4, no. 3-4, 25-54.

Paramskas, D. (1980). Integrating the laboratory into the curriculum. SPEAQ Journal, 4 , no. $3-4,129-148$.

Pill, G. (1974). Home-made or store-bought: two approaches to work in the laboratory. NALLD Journal, 8, no. 4, 18-21.

Schotta, S. (1973). Student evaluation and foreign language programs: a case study. Foreign Language Annals, 6, 500-518.

Sheehan, J. (1980). The state of the art: perspectives for the 1980's. SPEAQ Journal, 4, no. 3-4, 55-59.

Taggart, G. (1980). Language and communication in the 80 's: the role of the language laboratories. SPEAQ Journal, 4, no. 3-4, 19-23. 


\section{TABLE 1}

\section{RESPONSES BY LANGUAGE}

\section{Language}

Answer to

Spanish French Chinese Japanese German Russian [1] Question

\begin{tabular}{llllcccc}
\hline yes & 87 & 51 & 12 & 7 & 19 & 8 & 5 \\
no & 101 & 78 & 1 & 8 & 34 & 13 & 1 \\
\hline
\end{tabular}

$X 2=21.33$

d.f. $=8$

(1) Note: self-instructional

$N=425$

languages

$p-.01$

TABLE 2

RESPONSES BY COMMONLY TAUGHT AND LESS COMMONLY TAUGHT LANGUAGES

$\begin{array}{ll}\text { Answer to Question Commonly Taught } & \begin{array}{l}\text { Less Commonly } \\ \text { Taught }\end{array}\end{array}$

yes

165

19

no

226 
TABLE 3

RESPONSES OF FRENCH AND SPANISH STUDENTS IN

FIRST AND SECOND SEMESTERS

\begin{tabular}{lll}
\hline \multicolumn{2}{c}{ Semester } & \\
Answer to Question & First & Second \\
yes & 80 & 46 \\
no & 43 & 121 \\
& & \\
\hline
\end{tabular}

$\mathrm{X} 2=39.01$

d.f. $=1$

$N=290$

$p-.0001$

TABLE 4

FREQUENT COMMENTS BY BOTH YES AND NO STUDENTS

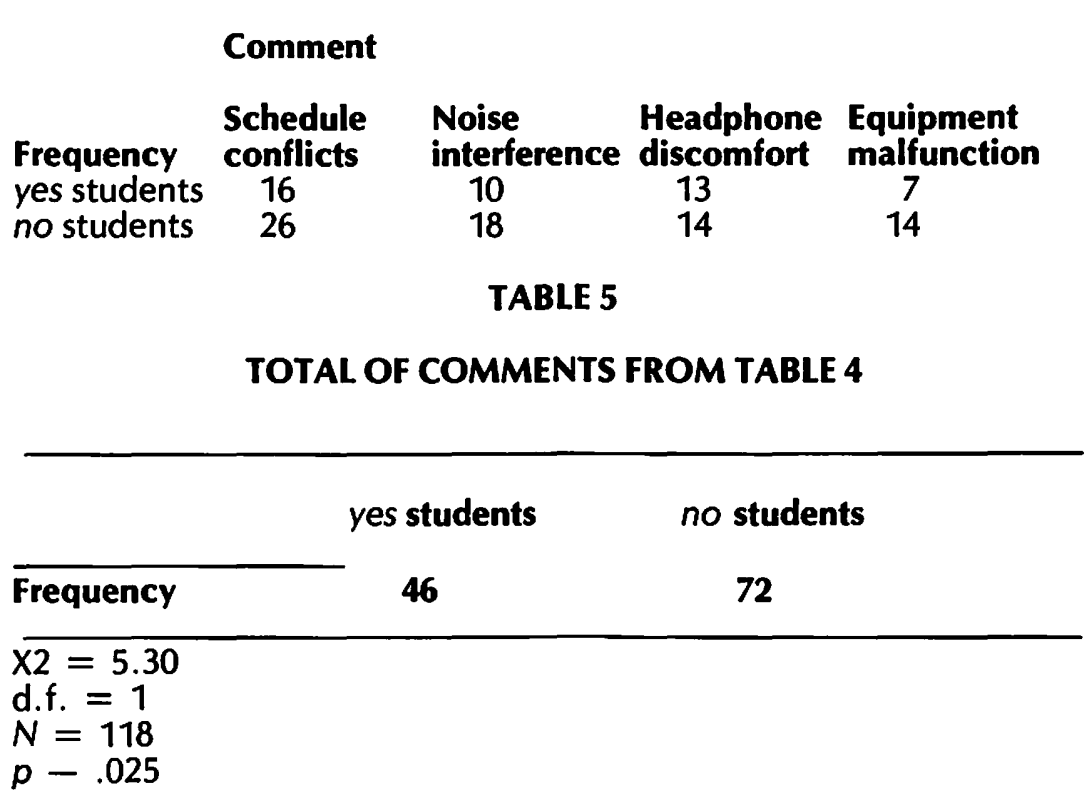


TABLE 6

STUDENT COMMENTS ON HELPFULNESS OF LAB

yes students

\begin{tabular}{lrr}
\hline lab helps & 23 & 8 \\
lab does not help & 0 & 19
\end{tabular}

$$
\begin{aligned}
& X 2=23.2 \\
& \text { d.f. }=1 \\
& N=50 \\
& p-.001
\end{aligned}
$$

The NALLD JOURNAL (New Advances in Learning Laboratory Developments ISSN 0027-5905) is currently published three times annually (Fall, Winter, Spring/Summer) by the International Association of Learning Laboratories (IALL). Mernbership in the Association is open to anyone associated with or interested in furthering the effective use of media in all areas of instruction. The membership year begins on October 1 and includes a subscription to the foumal.

Opinions expressed in signed articles are those of the authors. Although the Joumal editors attempt to. screen advertising for integrity, all advertising remains the responsibility of the advertiser. Neither opinions expressed in the articles nor advertising carry IALL approval unless specifically adopted by the IALL Executive Board. The NALLD Joumal is indexed in the Current Index of loumals in Education and is cited in Language and Language Behavioral Abstracts.

Rates: North America \$15; all other areas and institutions \$20; students $\$ 10$. Sustaining memberships $\$ 100$. Back issues are $\$ 5$ each. This publication is available on microfilm from: University Microfilms International, 300 North Zeeb Road, Dept. P.R., Ann Arbor, MI 48106 or 30-32 Mortimer St., Dept. P.R., London WIN 7RA, England.

Dues, subscriptions, changes of address, and orders for back issues should be sent to the Joumal at the address below. Payment is required in U.S. funds drawn on U.S. or Canadian banks. Make all checks payable to IALL. Advertising queries should be sent to Roger Sanchez-Berroa, Language Laboratory, Wesleyan University, Middletown, CT 06457.

POSTMASTER: Send Form 3579 to NALLD Joumal, Bingham Humanities 16. University of Louisville, KY 40292 . Third class postage paid at Louisville, Kentucky. Copyright 1984 by the International Association for Learning Laboratories. 


\section{This wireless language lab is portable... reliable... expandable ... and affordable!}

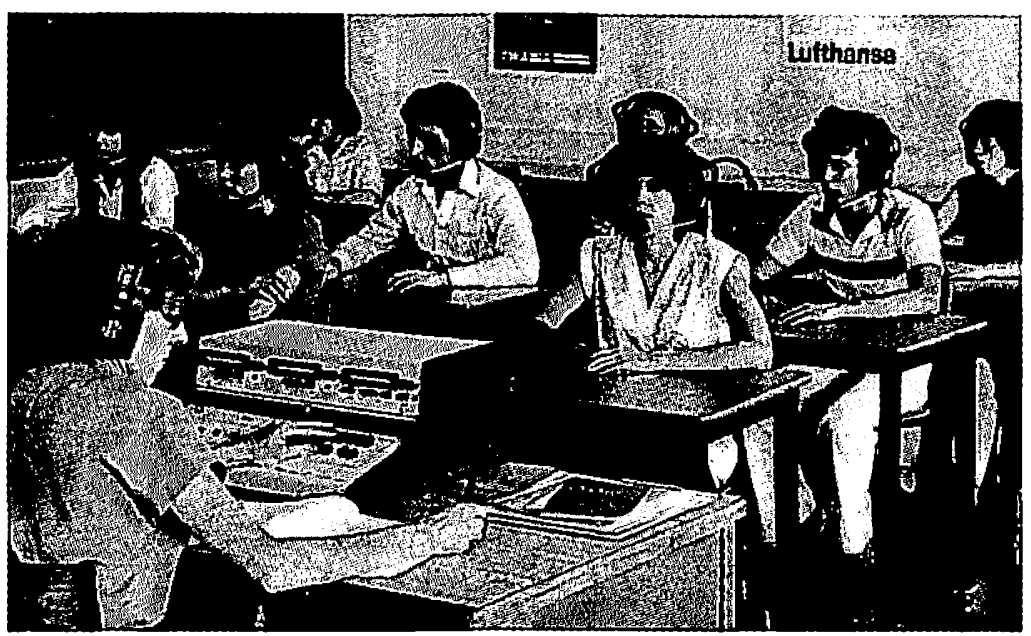

Only the MONI-COM III language laboratory offers all of these advantages:

- Wireless: permits unrestricted room use and student positioning at standard desks or tables.

- Portable: lightweight system takes up less space, can be stored in secure cabinet between classes or moved to other rooms.

- Reliable: designed and built by the most experienced lab manufacturer, with time-proven installations worldwide.

- Expandable: upgrade to a Level III lab any time with Portable Drill Recorders (for individual, dual track student recording) without obsoleting your present system - exclusive with $\mathrm{P} / \mathrm{H}$ wireless labs.

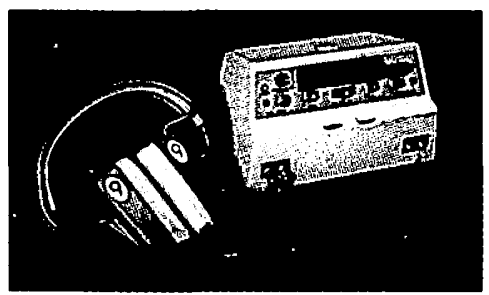

Portable Drill Recorder

- Affordable: maximum quality and wireless convenience at a lower price; no expensive installation or special furniture required.

$\mathrm{P} / \mathrm{H}$ also produces wireless systems for business education, libraries and media resource centers. In Ohio, educators call collect; outside Ohio, call toll-free $(800)$ 336-2219.

P/H ELECTRONICS, INC. 117 E. Helena Street

Dayton, Ohio 45404 (513) 461-5898 